https://helda.helsinki.fi

Spatial variations in bacterial and archaeal abundance and community composition in boreal forest pine mycorrhizospheres

Rinta-Kanto, Johanna M.

2020-04

Rinta-Kanto , J M \& Timonen , S 2020 , ' Spatial variations in bacterial and archaeal abundance and community composition in boreal forest pine mycorrhizospheres ' , European Journal of Soil Biology , vol. 97 , 103168 . https://doi.org/10.1016/j.ejsobi.2020.103168

http://hdl.handle.net/10138/340610

https://doi.org/10.1016/j.ejsobi.2020.103168

cc_by_nc_nd

acceptedVersion

Downloaded from Helda, University of Helsinki institutional repository.

This is an electronic reprint of the original article.

This reprint may differ from the original in pagination and typographic detail.

Please cite the original version. 


\title{
Spatial variations in bacterial and archaeal abundance and community composition in boreal forest pine mycorrhizospheres
}

\author{
Johanna M Rinta-Kanto ${ }^{1,2}$, Sari Timonen ${ }^{2}$ \\ ${ }^{1}$ Faculty of Engineering and Natural Sciences, Tampere University, P.O. Box 541, 33014 \\ Tampere University, Finland \\ ${ }^{2}$ Department of Microbiology, P. O. Box 56, 00014 University of Helsinki, Finland
}

\begin{abstract}
Mycorrhizal fungi have a strong impact on soil biota. In this study, bacterial and archaeal populations in different parts of Suillus bovinus - Pinus sylvestris mycorrhizospheres in boreal forest were quantified and identified by DNA analysis. The numbers of bacterial and archaeal 16S rRNA gene copies were highest in uncolonized humus and lowest in fruiting bodies. The numbers of bacterial $16 \mathrm{~S}$ rRNA gene copies varied from $1.3 \times 10^{7}$ to $3.1 \times 10^{9}$ copies $\mathrm{g}^{-1} \mathrm{fw}$ and archaeal copies from $4.1 \times 10^{7}$ to $9.6 \times 10^{8}$ copies $\mathrm{g}^{-1}$ fw. The relatively high number of archaeal 16S rRNA gene copies was likely due to the cold and highly organic habitat. The presence of hyphae appeared to further promote archaeal numbers and the archaea:bacteria ratio was over one in samples containing only fungal material. Most detected archaea belonged to terrestrial Thaumarchaeota. Proteobacteria, Actinobacteria and Acidobacteria were predictably the dominating bacterial taxa in the samples with clear trend of Betaproteobacteria preferring the pine root habitats.
\end{abstract}

Keywords: archaea, bacteria, ectomycorrhiza, microbial community, mycorrhizosphere, sporocarp 


\section{Introduction}

Plants release a significant percentage of fixed $\mathrm{C}$ below the ground via root exudation [1]. Tree root exudates are a rich source of nutrients for microbes in the soil. Root exudates include sugars, amino acids, organic acids, fatty acids and enzymes [2]. The quantity and quality of root exudates released to the surroundings depend on several factors, including plant species, soil type and degree and type of fungal colonization of the roots $[3,4]$. Labile carbon from the host plant is an important driver of the activity and composition of soil and root associated microbial community [5-7].

Mycorrhizospheres of different plants have been shown to support more distinct and diverse populations of bacteria [8] and archaea $[9,10]$ than bulk soil. Despite the obvious differences between habitats provided by plants or their mycorrhizal fungi, only a few studies have focused on the differences in microbial communities within the mycorrhizosphere. Even fewer studies have used culture independent methods to do this. Korkama et al. [11] used PLFA to show a positive relationship between ectomycorrhizal mycelia and bacteria in boreal forest soil. In contrast, dense ectomycorrhizal fungal mats formed by Piloderma in North American forest soil appeared to diminish the numbers of bacteria in one qPCR based study [12]. Fransson \& Rosling [13] showed that Scots pine associated hyphal fronts harbored bacterial populations distinct from any other mycorrhizosphere habitat. This was further confirmed by Timonen et al. [14] who also showed that exact locations defined the bacterial populations in ericoid mycorrhizospheres. It has been demonstrated that both bacterial and archaeal communities in uncolonized root tips are different than in root tips that have been colonized by ectomycorrhizal fungi $[15,16]$. Prokaryotic community structure in mycorrhizal 
root tips also vary temporally [17] and according to the physiological status of the plant [18].

Despite accumulating information about microbial community structure, not many studies have assessed the total abundance of bacteria and archaea in different habitats of the mycorrhizosphere. So far, studies have not compared the abundance and diversity of prokaryotes in multiple habitats within the mycorrhizosphere in the natural environment. In this study we have quantified bacteria and archaea using culture-independent methods and sequenced bacterial and archaeal 16S rRNA gene fragments to investigate prokaryotic diversity in multiple habitats within Pinus sylvestris - Suillus bovinus mycorrhizosphere in natural boreal forest environment.

\section{Materials and methods}

Sample collection site

All samples were collected from an approximately 70 year old dry pine Calluna type forest stand in Karjaa, Finland $\left(60^{\circ} 01^{\prime} \mathrm{N}, 23^{\circ} 34^{\prime} \mathrm{E}\right)$ in the autumn. Six randomly selected Suillus bovinus fruiting bodies of similar age verified by similar size and color of the hymenium, with a distance of minimum 10 meters from each other and the humus and roots directly beneath the fruiting body (approximately $15 \mathrm{~cm}$ depth), were collected using a garden shovel. The samples were placed in separate clean plastic bags and transported to the laboratory where they were stored at $+4^{\circ} \mathrm{C}$ until the next day. From each sample 5 different subsamples were collected: internal tissue (aseptically cut piece from base of the cap free of larval infestation) of the S. bovinus fruiting body (FB), S. bovinus external hyphae (EH), short roots of Pinus sylvestris (SR, short roots displaying no morphological changes induced by colonization by mycorrhizal fungi) without visible fungal colonization, mature mycorrhizas 
(MM, short roots colonized by Suillus bovinus connected to fruiting bodies), and uncolonized humus (UH, humus devoid of roots or Suillus bovinus hyphae, organic carbon content $40 \%$, temperature $5^{\circ} \mathrm{C}$ ). The subsample materials were placed in sterile $1.5 \mathrm{~mL}$ Eppendorf tubes and the fresh weight of each sample was recorded. The tubes were placed in $-20^{\circ} \mathrm{C}$ until DNA extraction. Prior to DNA extraction, each sample was homogenized by adding quartz sand and bead beating buffer from Ultra Clean Soil Kit (MoBio) and by grinding with a sterile pestle. The pre-homogenized material was transferred into the bead beating tubes of Ultra Clean Soil Kit (MoBio) and DNA was extracted according to the manufacturer's protocol.

\section{qPCR}

Abundances of bacterial and archaeal 16S rRNA gene copies were determined from six replicates of each sample type using quantitative PCR assays. Briefly, primers used for archaeal 16S rRNA gene quantification were Arch349F and Arch806R (Takai \& Horikoshi, 2000) and for eubacterial 16S rRNA gene quantification Eub338 and Eub518 (Fierer, et al., 2005). A standard for the archeal qPCR assay was generated by inserting a 16S rRNA gene fragment belonging to an uncultivated 1.1c-group Thaumarchaeon (NCBI accession number AM903348.1) into a vector pUC57. A 10-fold dilution series of the plasmid was used to generate a standard curve with concentrations ranging from $3 \times 10^{6}$ to $3 \times 10^{2}$ copies per reaction. A standard for the bacterial qPCR assay was generated by ligating a 16S rRNA gene fragment of Burkholderia glathei into a pJet 2.1 cloning vector. A 10-fold dilution series of the plasmid was used to generate a standard curve with concentrations ranging from $3 \times 10^{6}$ to 30 copies per reaction. Conditions for each assay were as described in detail in Rinta-Kanto et al. [19]. 
V3-V4 regions of bacterial 16S rRNA genes were PCR amplified from the original DNA using primers 341F and 758R [20] and sequenced with Illumina MiSeq at the Institute of Biotechnology at the University of Helsinki as described by Rinta-Kanto et al [21]. Archaeal 16S rRNA gene fragments were amplified from the original DNA with primers Arch349F 5'GYGCASCAGKCGMGAAW-3' and 539R 5'-GCBGGTDTTACCGCGGCGGCTGRCA-3' [22] and sequenced as described in Rinta-Kanto et al. [21].

\section{Bioinformatics}

Bacterial 16S rRNA reads were processed as follows: primers and sequencing adapters were removed using Cutadapt 1.10 with Python 2.7 .3 with command line parameters: -m 1 -e 0.2 O 15. Forward and reverse reads were joined using PEAR v0.9.6 (Zhang et al (2014)).

Quality filtering was done using Qiime version 1.9.1 [23] using phred_quality_threshold 19. Sequence length trimming, dereplication, and OTU clustering at $97 \%$ were done using vsearch v2.1.1 (Rognes et al 2016) as follows: sequences shorter than $350 \mathrm{nt}$ or longer than 450 nt were removed using command --fastx_filter; a set of unique sequences was generated using command --derep_fulllength; and unique sequences were clustered into OTUs at 97\% similarity threshold using vsearch command --cluster_fast with -id 0.97 --centroids. Chimera check (de novo) was done for the clustered sequences with vsearch command -uchime_denovo --sizein --xsize. The original quality-filtered, size-trimmed reads were mapped back to non-chimeric OTUs with command -usearch_global -strand plus -id 0.97. Subsequently, taxonomic assignment was done using blast (ref) and Silva data-base (release 123) (ref) using command assign_taxonomy.py in Qiime version 1.9.1 [23]. Sequences classified as mitochondria or chloroplast as well as singletons (OTUs represented by one sequence only) were removed from the data set prior to subsequent analyses. Subsequent steps were done in R-environment [24] using Phyloseq-package [25]. Due to large 
differences in library sizes, sequence libraries were subsampled to depth of 7228 sequences (Supplementary Table 1). Archaeal data sets were only handled through relative abundances with no further analyses on diversity. Differences in bacterial community composition in different habitats were analyzed by performing PCoA using unweighted Unifrac distance [26]. Statistical differences of bacterial community structure related to habitat were tested using permutational ANOVA using the function 'adonis' and differences in group dispersions were tested using function 'betadisper' in R-package vegan [27]. Distance-based redundancy analysis (db-RDA) was performed to evaluate the effect of environment in determining the differences in bacterial community structure. Statistical testing of the model was done with permutational anova-test. Archaeal $16 \mathrm{~S}$ reads were processed as described in Rinta-Kanto et al. [21].

Statistical testing for the qPCR data was done in the R environment [27] using packages car (Levene's test [28]) and stats (Kuskal-Wallis test, Pairwise Wilcoxon rank sum tests [24]).

Raw sequence data from this study have been deposited to the National Center of Biotechnology Information's Sequence Read Archive under study accession number PRJNA489999.

\section{Results}

Bacterial and archaeal abundance

The highest bacterial 16S rRNA gene copy abundances were found in uncolonized humus, $3.1 \times 10^{9}$ copies $\mathrm{g}^{-1} \mathrm{fw}$, and the lowest in $S$. bovinus fruiting body tissue, $1.3 \times 10^{7}$ copies $\mathrm{g}^{-1}$ fw (Fig. 1a). The numbers of bacterial 16S rRNA gene copies were between the 
abovementioned two extremes in all mycorrhizosphere habitats. Differences in bacterial 16S rRNA gene abundance in these habitats were statistically significant (Kruskal-Wallis-test, $\mathrm{p}<$ $0.05)$.

The archaeal 16S gene copy numbers followed the same trend as the bacterial ones. Copy numbers were lowest in fruiting body tissue and higher in short root and mycorrhizal tissue. Highest copy numbers were found in external hyphae as reliable quantification of archaeal gene copies in humus samples could not be obtained (Fig. 1b). Despite several attempts, we failed to get a single PCR product from uncolonized humus samples with archaeal primers and thus we were not able to reliably quantify the archaeal 16S rRNA gene copy abundance in these samples. Differences in abundances of archaeal 16S rRNA gene copies in mycorrhizosphere habitats were statistically significant (Kruskal-Wallis-test, $\mathrm{p}<0.05$ ).

Interestingly, the archaea:bacteria ratio was particularly high in samples containing fungal material. In external hyphae and fruiting bodies the ratio of archaea:bacteria was over one, which is exceptional in moderate environments (Fig. 1c). Overall the ratios in different habitats were statistically significantly different $(\mathrm{p}<0.05)$.

Sequence data sets

After quality filtering and removal of OTUs belonging to mitochondria, chloroplasts as well as singleton OTUs (OTUs represented by 1 sequence only), the bacterial 16S data set comprised 2357612 sequences, which clustered into 805 OTUs. After quality filtration and removal of non-archaeal OTUs and singleton OTUs, the archaeal 16S data set contained 506737 reads, which clustered into 171 OTUs. The archaeal reads were distributed among replicate samples very unevenly (Table S1). Bacterial community richness measured by the 
number of observed OTUs, was greatest in external hyphae and lowest in fruiting bodies and short roots (Fig. 2). The community richness comparison was based on the number of OTUs in the subsampled data set. The number of sequences in the humus samples was suspiciously low and thus they were excluded from the subsampled data set. Overall differences in community richness were statistically significant (Kruskal-Wallis test $\mathrm{p}<0.05$ ). There were too few different archaeal OTUs and they were too unevenly distributed among replicate samples to make reasonable assumptions about their community richness.

Bacterial community composition

Overall, unconstrained PCoA indicated that bacterial communities in different habitats were significantly different (adonis, $p=0.001$ ). Constrained dbRDA (Fig. 3) indicated that habitat explained $44 \%$ of the variance in microbial communities (permutational ANOVA $p=0.004$ )

Proteobacteria, Acidobacteria and Actinobacteria were the dominating bacterial groups in all the hypogeous samples (Fig. 4). Nevertheless, each habitat had a distinctive combination of taxa. Samples including pine root material (short roots and mycorrhizas) were dominated by Betaproteobacteria of which over $90 \%$ belonged to Burkholderiales (Supplementary Table 2). In addition to Betaproteobacteria mycorrhizal roots had a large proportion of Alphaproteobacteria (mainly Rhizobiales) and Actinobacteria (mainly Corynebacteriales). External mycelial bacterial populations shared features particularly with those of fruiting bodies and uncolonized humus. Bacterial populations of both external mycelia and fruiting bodies had relatively equal proportions of Betaproteobacteria, Alphaproteobacteria, Actinobacteria and Acidobacteria. Fruiting bodies contained also a rather large population of Phycispheraeae and Bacilli, not common in other habitats. External mycelia and uncolonized humus harbored the largest proportion of rare, small bacterial groups and unidentified 
bacteria.

Archaeal community composition

Based on archaeal 16S rRNA gene sequences, archaeal communities were mainly composed of taxa belonging to different Thaumarchaeota (Fig. 5). 1.3/MCG Thaumarchaeota formed the highest percentage of archaea in short roots, mycorrhizas and fruiting body tissue. Short roots contained also minor amounts of sequences of all detected types of archaea. Mycorrhizas harbored some MGI Thaumarchaeota and euryarchaeotal Thermoplasmata whereas fruiting body tissues included 20\% Terrestrial group 1.1c Thaumarchaeotal sequences. The largest proportion of the archaeal community in external hyphae and uncolonized humus was formed by Terrestrial group 1.1c Thaumarchaeota. Both habitats contained also some 1.3/MCG Thaumarchaeota. External mycelia harbored also a small population of SCG Thaumarchaeota and Thermoplasmata.

\section{Discussion}

It has been shown before that mycorrhizal fungi have an effect on archaeal and bacterial species composition in boreal forest soils e.g. [10, 13, 29, 12], but this is the first dataset reporting mycorrhizosphere effects on numbers of bacterial and archaeal 16S rRNA gene copies in different parts of mycorrhizospheres and archaeal:bacterial ratios. For the sake of clarity, although not biologically correct, in this discussion bacterial and archaeal 16S rRNA gene copy abundances are used as proxies for cell abundances.

Overall, the numbers of bacteria in root samples as well as in soil samples were similar to those found in other studies [14, 30-32]. The archaeal numbers were similar to those detected 
in rhizospheres of tall fescue [33], but clearly higher than those in the mycorrhizosphere study of conifers by Karlsson et al. [10]. One of the reasons behind the relatively high numbers of archaea we observed could be the temperature of soils. The samples in the current study were retrieved directly from the forest during autumn when the soil temperature was approximately $5{ }^{\circ} \mathrm{C}$. Soil samples in Jenkins et al. [33] were also taken directly from a field experiment, whereas samples in Karlsson et al. [10] were from microcosms grown in $22{ }^{\circ} \mathrm{C}$. Soil type and amount of humic components may also play a role as the soil in our study was organic humus and the field experiment by Jenkins et al. (2006) was watered with solution containing humic acid. The soil in the experiment of Karlsson et al. (2012) contained only 5 $\%$ of organic carbon.

There was a trend of prokaryote numbers being higher in external mycelia and uncolonized humus than in root samples. This is likely to be due to the higher number of easily available habitats in the finer grain materials. Nevertheless, this does not explain the different archaeal:bacterial ratios. The results indicate that the presence of $S$. bovinus promoted the numbers of archaea more than those of bacteria. In pine roots where the fungus was present, the ratio of archaea was higher than in roots without fungus. The fungal effect on the archaeal:bacterial ratio was visible also in the external mycelia, where the numbers of archaea were higher than the numbers of bacteria. Fungal exudates have been shown to promote archaeal populations also by Karlsson et al. [10]. Unfortunately, comparisons to the matrix where the hyphae live could not be made, as the quantitative results from uncolonized forest humus were inconclusive. The favorable effect of $S$. bovinus on archaea was most prominent in fruiting bodies, which do not contain plant material or are not in direct contact with humus. The archaea:bacteria ratio in fruiting bodies exceeded that of any other habitat. This is in line with a previous study by Rinta-Kanto et al. [21], where high archaeal 16S 
rRNA gene copy numbers were observed particularly in fruiting bodies of Boletales, including those of $S$. bovinus. It is rare in any moderate habitat to have more archaea than bacteria, but this appears to be the case in bolete fruiting bodies.

The variance of prokaryotic numbers within sample types was high. Thus, we were not able to find statistically significant differences using pairwise comparisons between habitats. One source of variation could be the different age of roots, mycorrhizas and external mycelia. Although on a longer time scale ( 2 years) bacterial communities associated with ectomycorrhizal roots appear mostly stable [15], bacterial communities associated with ectomycorrhizal fungi colonizing $P$. sylvestris root tips show significant temporal variability, especially at early stages of colonization [17]. However, temporal variability does not explain the variation between different fruiting bodies as they were similar in age. Soil is a quite variable matrix, which certainly adds to the variance in the detected prokaryotic numbers in soil samples.

Bacterial community composition varied significantly between habitats. In the forest humus uncolonized by S. bovinus mycelia, Alphaproteobacteria mostly belonging to Rhizobiales were clearly the dominating bacterial group and Acidobacteria the next most common group. This reinforces the results of the study by Timonen et al. [14] where forest humus was used as substrate for a growth cassette experiment in controlled laboratory conditions. Proteobacteria have copious numbers of enzymes for breaking down amino acids and organic acids [34] and some of them have the ability to fix atmospheric nitrogen [35], whereas Acidobacteria are proficient in catabolizing polysaccharides [36]. External mycelia had clearly the highest abundance of observed OTUs in all samples. The lower diversity in short roots and mycorrhizas was expected as many studies have shown that roots harbor a more 
specialized bacterial community than the surrounding, usually hyphae containing, soil and mycelia have several mechanisms which promote bacterial fitness $[37,38]$. In the external mycelia relatively high proportions of bacteria of the classes Alphaproteobacteria and Acidobacteria were detected similarly to the surrounding humus, but the presence of hyphae clearly promoted the populations of Actinobacteria and Planctomycetia. Bacteria of both these groups are known to be able to break down difficult organic compounds such as nitrogen containing chitin $[39,40]$. In this study, Betaproteobacteria classified primarily as Burkholderiales appeared to be enriched especially in mycorrhizas and short roots. Several previous studies have reported the enrichment of Burkholderiales in rhizospheres of several different tree species including Scots pine $[14,41-43]$ and in ectomycorrhizal root tips $[15$, 17]. All the abovementioned dominating bacterial groups have means of helping the soil community to gain biologically available nitrogen either via nitrogen fixation or organic matter degradation. This may be a crucial advantage in the nitrogen limited organic soil environment of boreal forest.

The archaeal OTUs found in external mycelia and uncolonized humus were mainly $1.1 \mathrm{c}$ terrestrial Thaumarchaeota. Most of these were identical or very similar to those found from pine mycorrhizospheres and boreal forest humus previously [9, 44]. The function of 1.1c Thaumarchaeota is not yet clear, but there are indications that they would be important in metabolizing small carbon products such as methanol and methane [45] and prefer organic nitrogen as their source of nitrogen [46]. Surprising numbers of OTUs were classified as 1.3 terrestrial/MCG Thaumarchaeota. These archaeal types have not been very abundant in previous studies of boreal humus pine mycorrhizospheres where the 1.1c Thaumarchaeota have been clearly dominant $[29,47]$. Although 1.3 terrestrial/MCG Thaumarchaeota have been mainly reported from aquatic environments, according to the NCBI database they have 
also been found from different soil and rhizospheric environments.

\section{Conclusions}

Numbers of 16S rRNA gene copies of bacteria were on the expected level while the numbers of archaeal were on the higher end of the spectrum observed in the earlier studies. This may be due to the cold and highly organic habitat. The presence of hyphae appeared to promote archaeal numbers. There were more archaea than bacteria both in $S$. bovinus fruiting bodies and external mycelia, which is exceptional in moderate habitats.

\section{Acknowledgements}

This work was funded by Finnish Academy grant no. 131819.

\section{References}

[1] C.D. Campbell, S.J. Grayston, D.J. Hirst, Use of rhizosphere carbon sources in sole carbon source tests to discriminate soil microbial communities, Journal of Microbiological Methods, 30 (1997) 33-41.

[2] S.J. Grayston, D. Vaughan, D. Jones, Rhizosphere carbon flow in trees, in comparison with annual plants: the importance of root exudation and its impact on microbial activity and nutrient availability, Applied Soil Ecology, 5 (1996) 29-56.

[3] S. Timonen, K.S. Jørgensen, K. Haahtela, R. Sen, Bacterial community structure at defined locations of Pinus sylvestris -Suillus bovinus and -Paxillus involutus mycorrhizospheres in dry pine forest humus and nursery peat, Canadian Journal of 
Microbiology, 44 (1998) 499-513.

[4] P. Fransson, A. Andersson, S. Norstrom, D. Bylund, E. Bent, Ectomycorrhizal exudates and pre-exposure to elevated $\mathrm{CO} 2$ affects soil bacterial growth and community structure, Fungal Ecol, 20 (2016) 211-224.

[5] R.G. Linderman, Mycorrhizal interactions with the rhizosphere microflora: the mycorrhizosphere effect, Phytopathology, 78 (1988) 367-370.

[6] M.N. Hogberg, P. Hogberg, D.D. Myrold, Is microbial community composition in boreal forest soils determined by $\mathrm{pH}, \mathrm{C}$-to-N ratio, the trees, or all three? Oecologia, 150 (2007) $590-601$.

[7] W. de Boer, L.B. Folman, R.C. Summerbell, L. Boddy, Living in a fungal world: impact of fungi on soil bacterial niche development, FEMS Microbiology Reviews, 29 (2005) 795 811.

[8] S. Llado, R. Lopez-Mondejar, P. Baldrian, Forest Soil Bacteria: Diversity, Involvement in Ecosystem Processes, and Response to Global Change, Microbiology and Molecular Biology Reviews, 81 (2017).

[9] M. Bomberg, S. Timonen, Effect of Tree Species and Mycorrhizal Colonization on the Archaeal Population of Boreal Forest Rhizospheres, Applied and Environmental Microbiology, 75 (2009) 308-315.

[10] A.E. Karlsson, T. Johansson, P. Bengtson, Archaeal abundance in relation to root and fungal exudation rates, FEMS Microbiology Ecology, 80 (2012) 305-311.

[11] T. Korkama, H. Fritze, A. Pakkanen, T. Pennanen, Interactions between extraradical ectomycorrhizal mycelia, microbes associated with the mycelia and growth rate of Norway spruce (Picea abies) clones, New Phytologist, 173 (2007) 798-807.

[12] L.A. Kluber, J.E. Smith, D.D. Myrold, Distinctive fungal and bacterial communities are associated with mats formed by ectomycorrhizal fungi, Soil Biology \& Biochemistry, 43 
(2011) 1042-1050.

[13] P. Fransson, A. Rosling, Fungal and bacterial community responses to Suillus variegtus extraradical mycelia and soil profile in Scots pine microcosms, Plant and Soil, 385 (2014) $255-272$.

[14] S. Timonen, H. Sinkko, H. Sun, O.M. Sietio, J.M. Rinta-Kanto, H. Kiheri, J. Heinonsalo, Ericoid Roots and Mycospheres Govern Plant-Specific Bacterial Communities in Boreal Forest Humus, Microbial Ecology, 73 (2017) 939-953.

[15] N.H. Nguyen, T.D. Bruns, The Microbiome of Pinus muricata Ectomycorrhizae: Community Assemblages, Fungal Species Effects, and Burkholderia as Important Bacteria in Multipartnered Symbioses, Microbial Ecology, 69 (2015) 914-921.

[16] M. Bomberg, G. Jurgens, A. Saano, R. Sen, S. Timonen, Nested PCR detection of archaea in defined compartments of pine mycorrhizospheres developed in boreal forest humus microcosms, FEMS Microbiology Ecology, 43 (2003) 163-171.

[17] S. Marupakula, S. Mahmood, R.D. Finlay, Analysis of single root tip microbiomes suggests that distinctive bacterial communities are selected by Pinus sylvestris roots colonized by different ectomycorrhizal fungi, Environmental Microbiology, 18 (2016) 14701483.

[18] H. Izumi, Contrasting responses of the bacterial communities in ectomycorrhizal roots and rhizosphere soils to defoliation or winter hardening, Rhizosphere, 8 (2018) 8-11. [19] J.M. Rinta-Kanto, H. Sinkko, T. Rajala, W.A. Al-Soud, S.J. Sorensen, M.V. Tamminen, S. Timonen, Natural decay process affects the abundance and community structure of Bacteria and Archaea in Picea abies logs, FEMS Microbiology Ecology, 92 (2016). [20] G. Muyzer, E.C. DeWaal, A.G. Uitterlinden, Profiling of complex microbial populations by denaturing gradient gel electrophoresis analysis of polymerase chain reaction-amplified genes coding for 16SrRNA, Applied and Environmental Microbiology, 59 (1993) 395-700. 
[21] J.M. Rinta-Kanto, K. Pehkonen, H. Sinkko, M.V. Tamminen, S. Timonen, Archaea are prominent members of the prokaryotic communities colonizing common forest mushrooms, Canadian Journal of Microbiology, 64 (2018) 716-726.

[22] K. Takai, K. Horikoshi, Rapid detection and quantification of members of the archaeal community by quantitative PCR using fluorogenic probes, Applied and Environmental Microbiology, 66 (2000) 5066-+.

[23] J.G. Caporaso, J. Kuczynski, J. Stombaugh, K. Bittinger, F.D. Bushman, E.K. Costello, N. Fierer, A.G. Pena, J.K. Goodrich, J.I. Gordon, G.A. Huttley, S.T. Kelley, D. Knights, J.E. Koenig, R.E. Ley, C.A. Lozupone, D. McDonald, B.D. Muegge, M. Pirrung, J. Reeder, J.R. Sevinsky, P.J. Tumbaugh, W.A. Walters, J. Widmann, T. Yatsunenko, J. Zaneveld, R. Knight, QIIME allows analysis of high-throughput community sequencing data, Nat Methods, 7 (2010) 335-336.

[24] R.C. Team, R: A Language and Environment for Statistical Computing, R Foundation for Statistical Computing, Vienna, Austria, 2015.

[25] P.J. McMurdie, S. Holmes, phyloseq: An R Package for Reproducible Interactive Analysis and Graphics of Microbiome Census Data, Plos One, 8 (2013).

[26] C. Lozupone, R. Knight, UniFrac: a new phylogenetic method for comparing microbial communities, Applied and Environmental Microbiology, 71 (2005) 8228-8235.

[27] J. Oksanen, F. Blanchet, R. Kindt, P. Legendre, P. Minchin, R. O'Hara, G. Simpson, P. Solymos, M. Stevens, H. Wagner, Vegan: Community Ecology Package. http://CRAN.Rproject.org/package=vegan R package version 2.3-3., in, 2016.

[28] J. Fox, S. Weisberg, An $\{R\}$ Companion to Applied Regression, 2nd ed., Thousand Oaks Sage, CA, 2011.

[29] M. Bomberg, S. Timonen, Distribution of Cren- and Euryarchaeota in Scots pine mycorrhizospheres and boreal forest humus, Microbial Ecology, 54 (2007) 406-416. 
[30] V. Torsvik, L. Ovreås, T. Thingstad, Prokaryotic diversity - Magnitude, dynamics, and controlling factors, Science, 296 (2002) 1064-1066.

[31] L.J. Smets W, Bradford MA, McCulley RL, Lebeer S, Fierer N, A method for simultaneous measurement of soil bacterial abundances and community composition via $16 \mathrm{~S}$ rRNA gene sequencing, PeerJPrePrints, https://dx.doi.org/10.7287/peerj.preprints.1318v1 | CC-BY 4.0 Open Access | rec: 21 Aug 2015 (2015).

[32] B. Reinhold-Hurek, W. Bunger, C.S. Burbano, M. Sabale, T. Hurek, Roots Shaping Their Microbiome: Global Hotspots for Microbial Activity, Annu Rev Phytopathol, 53 (2015) 403-+.

[33] M.B. Jenkins, A. Franzluebbers, S. Humayoun, Assessing short-term responses of prokaryotic communities in bulk and rhizosphere soils to tall fescue endophyte infection, Plant and Soil, 289 (2006) 309-320.

[34] K.G. Eilers, C.L. Lauber, R. Knight, N. Fierer, Shifts in bacterial community structure associated with inputs of low molecular weight carbon compounds to soil, Soil Biology \& Biochemistry, 42 (2010) 896-903.

[35] R. Garrido-Oter, R.T. Nakano, N. Dombrowski, K.W. Ma, A.C. McHardy, P. SchulzeLefert, A. Team, Modular Traits of the Rhizobiales Root Microbiota and Their Evolutionary Relationship with Symbiotic Rhizobia, Cell Host Microbe, 24 (2018) 155-+.

[36] S. Llado, L. Zifcakova, T. Vetrovsky, I. Eichlerova, P. Baldrian, Functional screening of abundant bacteria from acidic forest soil indicates the metabolic potential of Acidobacteria subdivision 1 for polysaccharide decomposition, Biology and Fertility of Soils, 52 (2016) 251-260.

[37] U. Vik, R. Logares, R. Blaalid, R. Halvorsen, T. Carlsen, I. Bakke, A.B. Kolsto, O.A. Okstad, H. Kauserud, Different bacterial communities in ectomycorrhizae and surrounding soil, Sci Rep-Uk, 3 (2013). 
[38] R. Nazir, J.A. Warmink, H. Boersma, J.D. van Elsas, Mechanisms that promote bacterial fitness in fungal-affected soil microhabitats, FEMS Microbiology Ecology, 71 (2010) 169185.

[39] M.E. Lacombe-Harvey, R. Brzezinski, C. Beaulieu, Chitinolytic functions in actinobacteria: ecology, enzymes, and evolution, Applied Microbiology and Biotechnology, 102 (2018) 7219-7230.

[40] N.V. Ravin, A.L. Rakitin, A.A. Ivanova, A.V. Beletsky, I.S. Kulichevskaya, A.V. Mardanov, S.N. Dedysh, Genome Analysis of Fimbriiglobus ruber SP5(T), a Planctomycete with Confirmed Chitinolytic Capability, Applied and Environmental Microbiology, 84 (2018).

[41] G. Bonito, H. Reynolds, M.S. Robeson, J. Nelson, B.P. Hodkinson, G. Tuskan, C.W. Schadt, R. Vilgalys, Plant host and soil origin influence fungal and bacterial assemblages in the roots of woody plants, Molecular Ecology, 23 (2014) 3356-3370.

[42] S. Uroz, P. Oger, E. Morin, P. Frey-Klett, Distinct Ectomycorrhizospheres Share Similar Bacterial Communities as Revealed by Pyrosequencing-Based Analysis of 16S rRNA Genes, Applied and Environmental Microbiology, 78 (2012) 3020-3024.

[43] H. Izumi, I.C. Anderson, I.J. Alexander, K. Killham, E.R.B. Moore, Endobacteria in some ectomycorrhiza of Scots pine (Pinus sylvestris), FEMS Microbiology Ecology, 56 (2006) 34-43.

[44] K. Yrjala, R. Katainen, G. Jurgens, U. Saarela, A. Saano, M. Romantschuk, H. Fritze, Wood ash fertilization alters the forest humus Archaea community, Soil Biology \& Biochemistry, 36 (2004) 199-201.

[45] M. Bomberg, L. Montonen, S. Timonen, Anaerobic Eury- and Crenarchaeota inhabit ectomycorrhizas of boreal forest Scots pine, European Journal of Soil Biology, 46 (2010) 356-364. 
[46] E.B. Weber, L.E. Lehtovirta-Morley, J.I. Prosser, C. Gubry-Rangin, Ammonia oxidation is not required for growth of Group 1.1c soil Thaumarchaeota, FEMS Microbiology Ecology, $91(2015)$.

[47] S. Timonen, M. Bomberg, Archaea in dry soil environments, Phytochem Rev, 8 (2009) $505-518$.

\section{Figure legends}

Fig. 1. Abundance of bacterial (A) and archaeal (B) 16S rRNA gene copies and the ratio of archaeal to bacterial 16S rRNA gene copy abundance (C) in different habitats. In box and whisker plots, the solid line inside the box represents the median and the dashed line represents the mean of the values $(n=3)$. Short roots $(S R)$, mature mycorrhizas $(M M)$, external hyphae (EH), fruiting body (FB), uncolonized humus (UH).

Fig. 2. Richness of bacterial population expressed as number of observed OTUs. The presented values are the means of three replicates and the error bars represent the standard deviations. Short roots (SR), mature mycorrhizas (MM), external hyphae (EH), fruiting body (FB), uncolonized humus (UH).

Fig. 3. Distance-based Redundancy Analysis (db-RDA) of bacterial populations in different habitats. The ordination is based on unweighted Unifrac distance. Short roots (SR), mature mycorrhizas (MM), external hyphae (EH), fruiting body (FB), uncolonized humus (UH).

Fig. 4. Taxonomic composition of bacterial communities in different sample types. Short roots (SR), mature mycorrhizas (MM), external hyphae (EH), fruiting body (FB), 
uncolonized humus (UH).

Fig. 5. Taxonomic composition of archaeal communities in different sample types. Short roots $(\mathrm{SR})$, mature mycorrhizas $(\mathrm{MM})$, external hyphae $(\mathrm{EH})$, fruiting body $(\mathrm{FB})$, uncolonized humus $(\mathrm{UH}) . \mathrm{MCG}=$ Miscellaneous Crenarchaeotic Group, $\mathrm{MGI}=$ Marine group I, SCG = Soil Crenarchaeotic Group. 
Figure 1
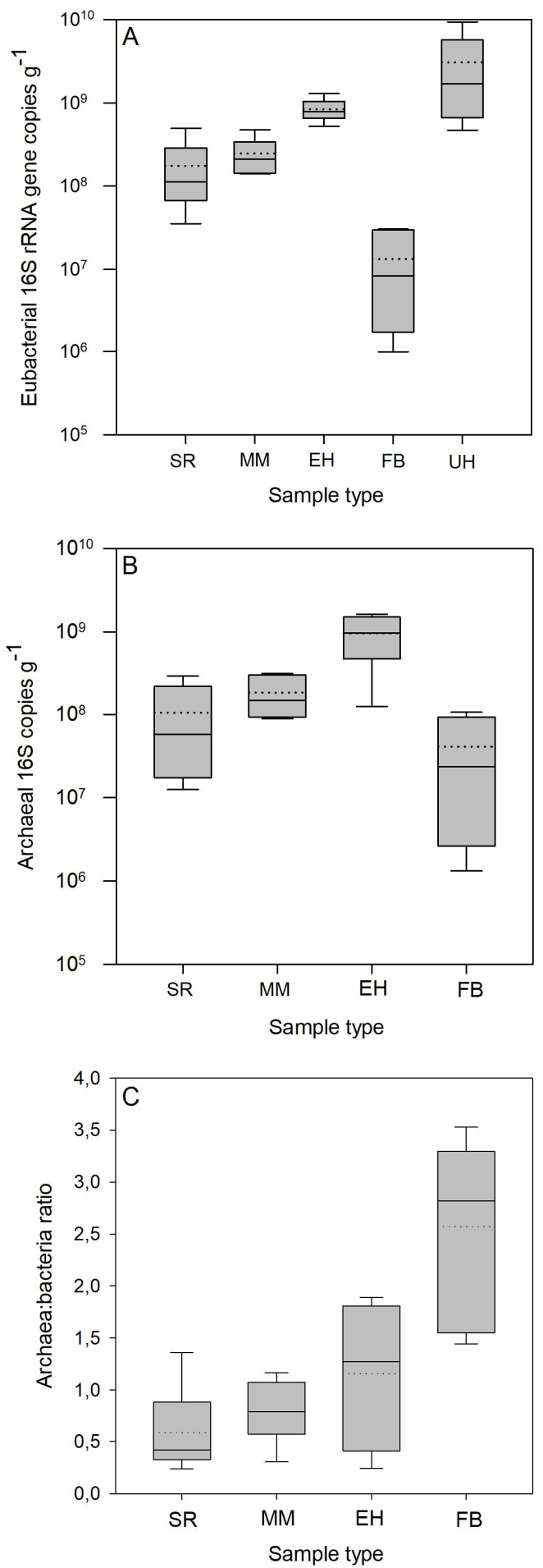
Figure 2

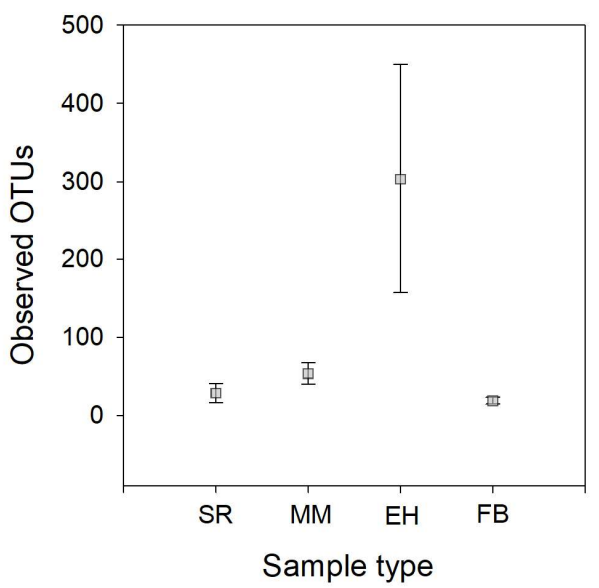




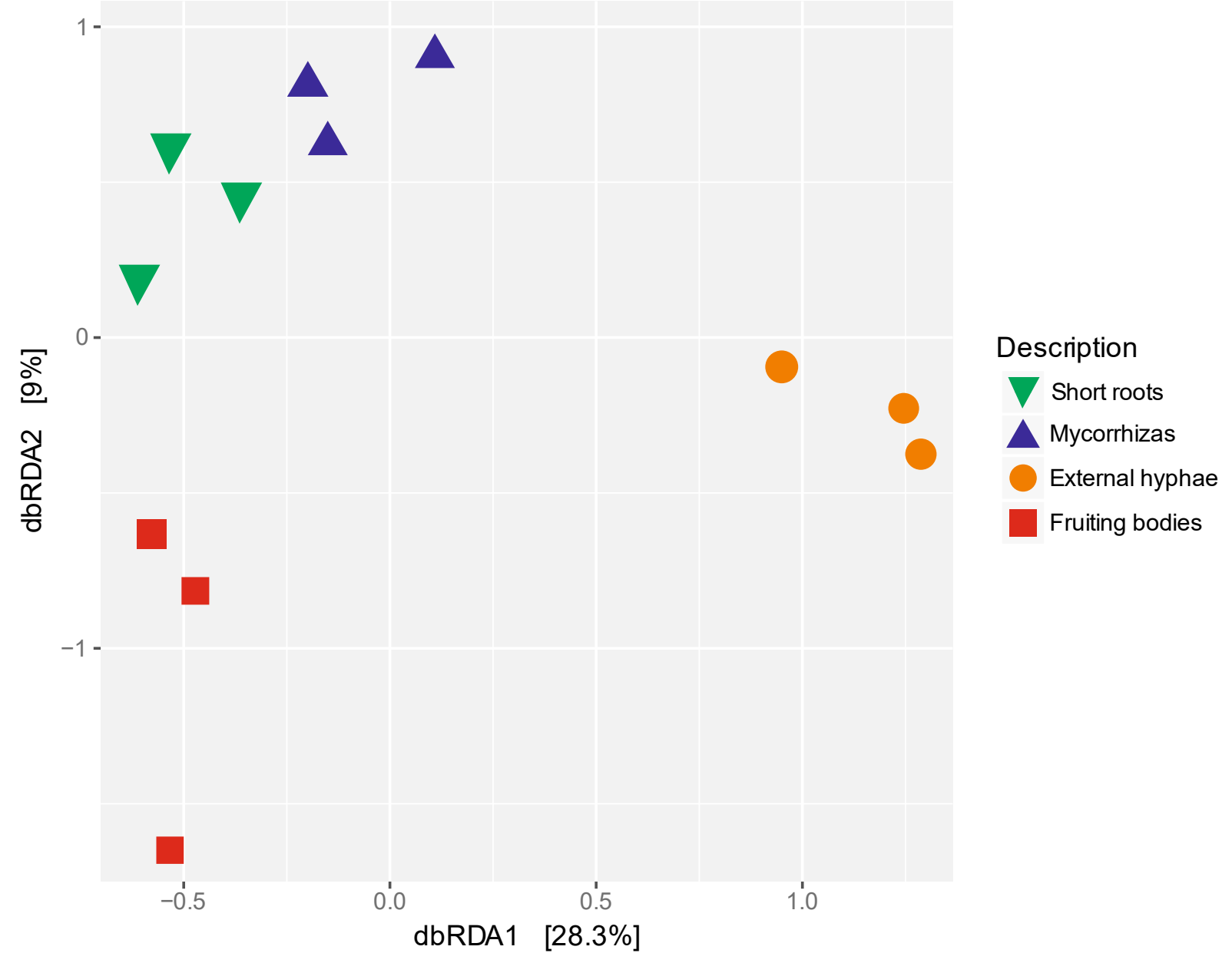




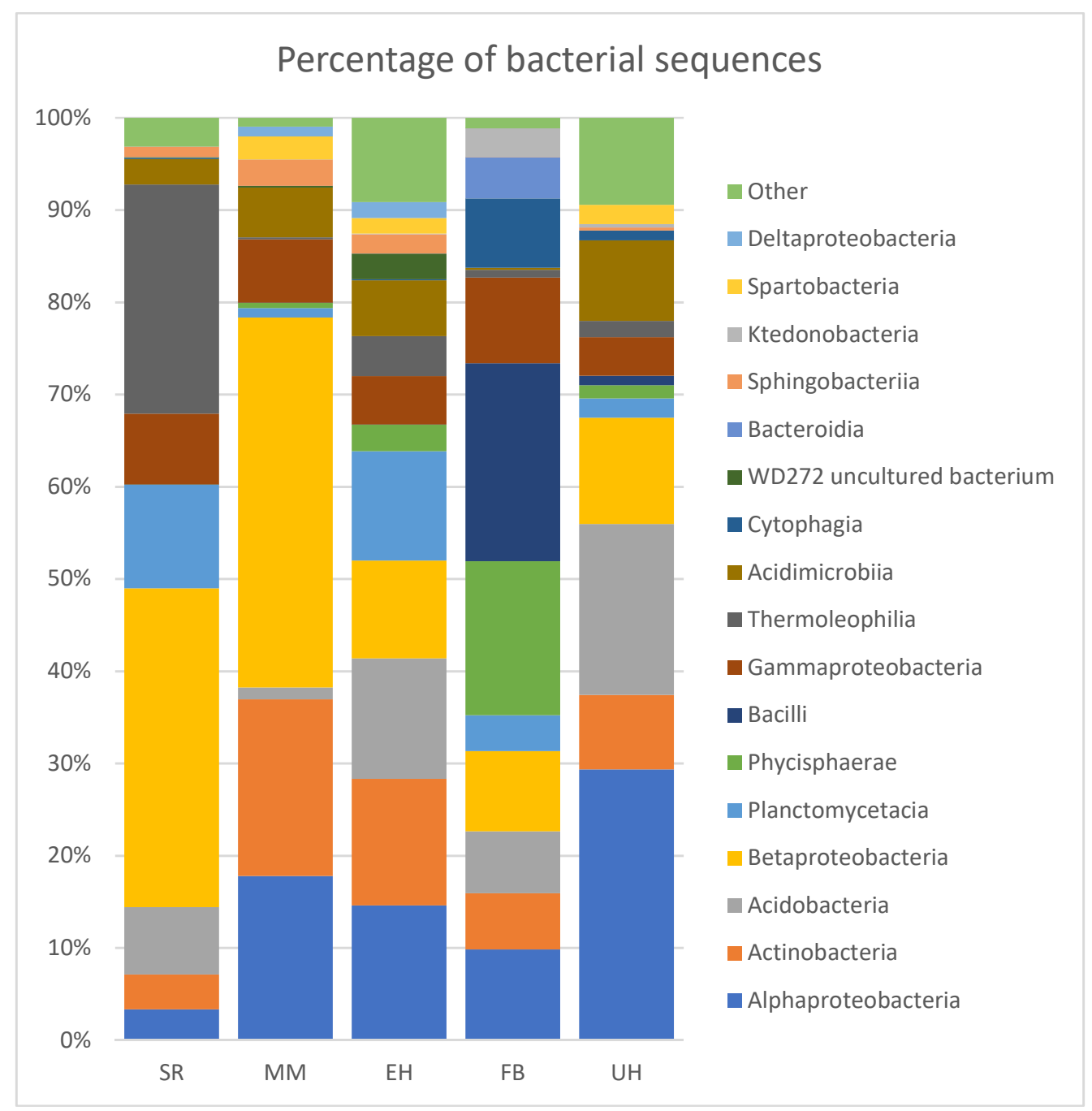




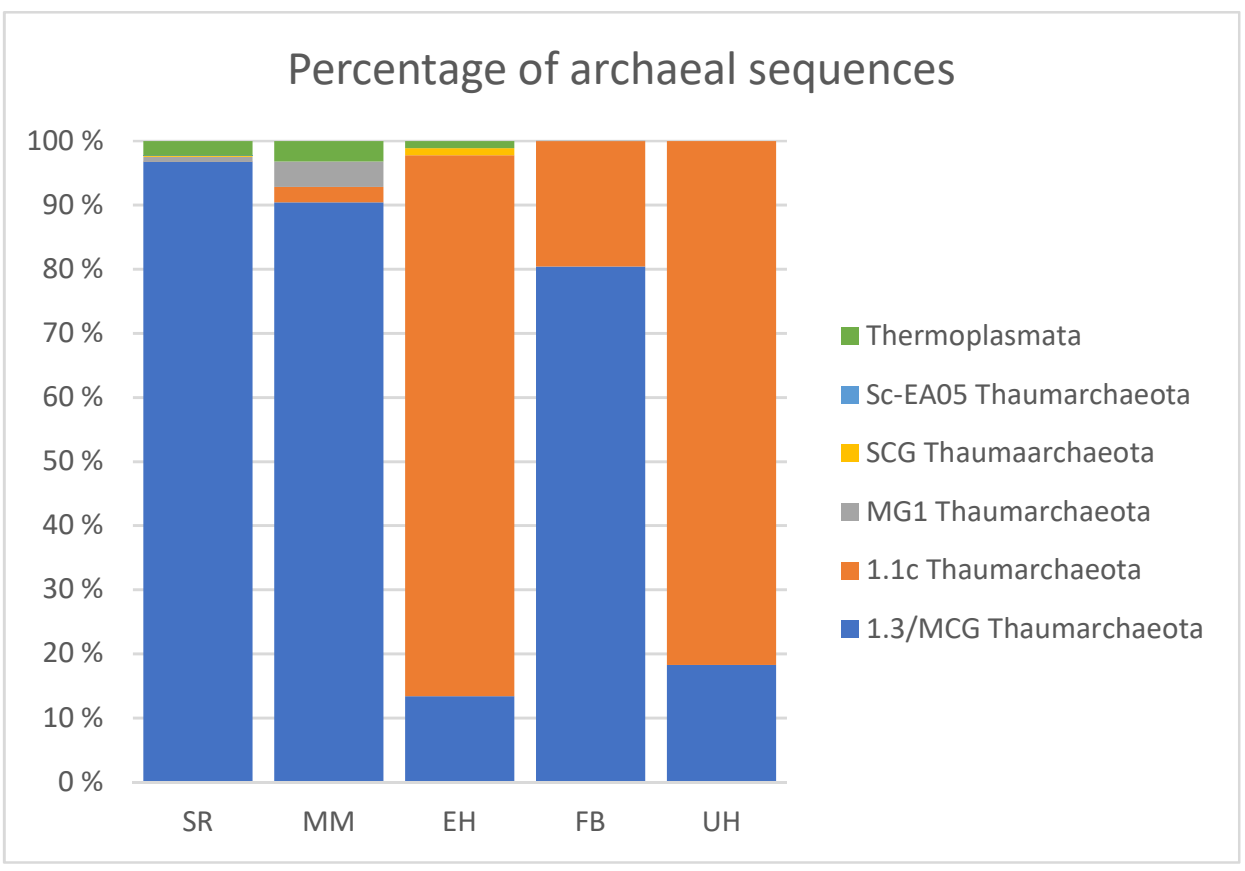

